\title{
Lexis
}

Journal in English Lexicology

Book reviews | 2020

\section{Pius Ten HACKEN (ed.), The Semantics of Compounding}

Cambridge University Press, 2016, 264 pages

\section{Cathy Parc}

\section{(2) OpenEdition}

Journals

\section{Electronic version}

URL: http://journals.openedition.org/lexis/4527

DOI: $10.4000 /$ lexis.4527

ISSN: 1951-6215

\section{Publisher}

Université Jean Moulin - Lyon 3

\section{Electronic reference}

Cathy Parc, "Pius Ten hacken (ed.), The Semantics of Compounding", Lexis [Online], Book reviews, Online since 12 July 2020, connection on 09 April 2021. URL: http://journals.openedition.org/lexis/4527 ; DOI: https://doi.org/10.4000/lexis.4527

This text was automatically generated on 9 April 2021.

\section{(c) (i) (9)}

Lexis is licensed under a Creative Commons Attribution-NonCommercial-NoDerivatives 4.0 International License. 


\section{Pius Ten HACKEN (ed.), The Semantics of Compounding}

Cambridge University Press, 2016, 264 pages

Cathy Parc

\section{REFERENCES}

Pius Ten Hacken (ed.)

The Semantics of Compounding, Cambridge university Press, 2016. ISBN:

978-1-107-09970-8, Price: 87,97€, 264 pages.

\section{General observations}

1 Pius ten Hacken is Professor of Translation Studies at Innsbruck University. He has published articles in specialized journals like Linguistische Berichte Sonderheft, Quaderns de Filología: Estudis lingüistics, SKASE Journal of Theoretical Linguistics, Kwartalnik Neofilologiczny or CORELA. He has released chapters or whole books mostly on morphology ever since 1994. He "has worked on the machine translation project Eurotra and at universities in Basel (Computer Science and General Linguistics) and Swansea (French and Translation Studies)" (p. i).

\section{Synopsis of the book}

\subsection{Introduction}

2 The eleven pages written by Pius ten Hacken, which are very clear, correspond to the first chapter where the semantic dimension is emphasized from the outset. It soon becomes obvious that the book, which "was inspired by a workshop organized at the $19^{\text {th }}$ Congrès International des Linguistes / International Congress of Linguists, which 
took place in Geneva from 21 to 27 July 2013" (p.x), is aimed at specialists or advanced level students. For instance, the abbreviations used page 1 in the phrase "RDPs and Variable R" are only explained page 3. The author chooses a historical point of view to take stock of the research carried out on compounds: he goes back to the 1960s where you can find "The oldest generative account of compounds" (p. 2) and quotes the main references - R. Lees, J. Katz as well as P. Postal - before mentioning J. Levi and M. Allen in the late 1970s or E. Selkirk in the 1980s. He discusses their theories, analyses the interplay of influences and does not evade the main problems: trying to find solutions implies detailing a particular linguistic framework so as to see how to improve it. That is why he focuses on three of them: Ray Jackendoff's [2002], Rochelle Lieber's [2004] and Pavol Štekauer's [1998, 2005]. The book is thus composed of articles by various European and American contributors who have chosen one of these theories, the most represented being R. Jackendoff's. The content is quite abstract because of this theoretical angle, but also concrete thanks to the numerous examples provided from the start. The cross-language approach enables the contributors to reach a wider readership, the questions of linguistic borrowing and of potential intersections between languages being at stake.

3 There are three parts: the first is devoted to "Frameworks" (p. 13-68), the second to "Noun-noun compounds" (p.69-149) and the third to "Other compound types" (p. 151-207), which makes for a logical line of reasoning. As stated by the author, chapter 12, which is entitled "Three analyses of compounding: a comparison" and spans 22 pages, serves as a conclusion. It offers a comparison between the three frameworks and reflects the editor's open-mindedness as readers can select the theory they prefer: they can easily see which is most appropriate depending on the exemplars and the context.

The 14-page References section is organized in alphabetical order and it is a pity to notice that no categories whatsoever have been defined. Hinged on either the nature of the document or the theory under study, they could have facilitated the reader's choices.

The 5-page Author index is very useful and quite detailed given that under the author's name each work is designated by its year of publication, itself followed by the page number of the quotes in the present book. What is more, the links to other references which might be useful within a discussion have been added. The 3-page Subject index includes lower- and upper-case words, among which some are synthesized by their abbreviations within brackets, while cross-references are introduced by the phrase "see also". Hence, it is easy for the reader to learn more on a given topic.

\section{Detailed presentation of each chapter}

\subsection{Chapter 2, "English noun-noun compounds in Conceptual Semantics" by Ray Jackendoff}

By asking R. Jackendoff to write the first chapter himself, P. ten Hacken has enabled us to know more about one of the three theoretical frameworks on which the book focuses, which is a good idea. Within the framework of "Conceptual Semantics" (p. 18), which "incorporates a great deal of what is usually called pragmatics" (p. 18), the main tenets are linked to "the Head Principle" or to such linguistic phenomena as coinage, 
"recursivity" and interpretation. As far as the latter is concerned, two factors come into play according to the author of this article:

semantic interpretation is highly dependent on the pragmatics of the words being combined and on the contextual specifics of use. The language-user must home in on the intended meaning of a novel compound by making use of (a) the semantic details of the constituent words and (b) the discourse and extralinguistic context.

Syntax does not give much support. (p. 18)

When analyzing compounds, you have to keep in mind rules without forgetting exceptions and ask yourself whether paraphrasing is possible or not as you have to take into consideration "the limits of compositionality" (p. 18). R. Jackendoff suggests "the simple event schema" (p.20), the phrase "event schema" being borrowed from R. Langacker [1987] as well as C. Fillmore and S. Atkins [1992]. He defines as "promiscuous (by contrast with ambiguous)" (p. 20) words like boxcar or pontoon bridge that can have multiple meanings "simultaneously, in cooperation rather than in competition" (p. 20). Other keywords he relies on are "profiling" (p.21), "action modality" (p.22) and "cocomposition" (p. 24), which he passes in review before pondering in more detail "the Head Principle and the Argument Schema" (p. 25) along with "the Modifier Schema" (p. 26).

"Given two nouns $\mathrm{N}_{1}$ and $\mathrm{N}_{2}$ that mean $X_{1}$ and $Y_{2}$ respectively" and $\mathrm{F}$ being the "function $F\left(X_{1}, Y_{2}\right)$ that yields the meaning of the compound $\left[\mathrm{N}_{1} \mathrm{~N}_{2}\right]$ " (p. 18), he proposes "thirteen basic functions" (p. 27) to help classify compounds, which are very convenient and easy to use. They are: $\operatorname{CLASSIFY}(X, Y), B E(Y, X)$, SIMILAR (X, Y), KIND (X, Y), BE (X, AT/IN/ON Y), COMP (X, Y), MADE (X, FROM Y), PART (X, Y), CAUSE (X, Y), MAKE (X, Y), X serves as $Y$, HAVE (X, Y), PROTECT (X, Y, FROM Z). He then hints at the possibility of there being more relations, as many as twenty or thirty, as a result of "all the variants and reversibility" (p.31). To illustrate his theory, he has a look at some locative relations around such examples as water fountain, coal mine or gas pipe among others, which permits him to use material from the meanings of $\mathrm{N}_{1}$ and $\mathrm{N}_{2}$. The last section, which is devoted to "generative schemata for $F$ " (p. 33-35), shows how basic functions can overlap and how proper function has to be factored in when construing the meaning of some compounds like barbershop or piano bench. Others like pig tail or sea horse exemplify "metaphor coercion" (p. 34-35), which is tackled before the "closing remarks" of this thought-provoking paper.

\subsection{Chapter 3, "Compounding in the lexical semantic framework" by Rochelle Lieber}

$7 \quad$ R. Lieber presents her own framework in three parts and deals with compounds and their interpretation from a morphological point of view. She uses two metaphors in her theory: that of "the semantic skeleton which contains those aspects of lexical and affixal meaning that are syntactically relevant" and that of "the semantic body which contains all aspects of meaning that are encyclopedic in nature" (p. 38). The term "skeleton", which might not be considered a fine one especially for the study of modern languages that keep evolving, proves problematic since the corresponding concept does not apply to all compounds. As such it does not contribute to a comprehensive coherent framework, contrary to the tools used by her fellow theoreticians: 
For these compounds [coordinate ones], as with the attributive compounds discussed in the next section, we cannot rely merely on the skeletons of the compounded elements to explain the range of possible interpretations. (p. 47) difficult one to handle too though the starting point is S. Scalise and A. Bisetto's 2009 clear classification of compounds. Their three categories are taken up - subordinate, coordinate and attributive - while a further distinction is made between endocentric and exocentric compounds. R. Lieber, who talks about "affixation" as opposed to "compounding", analyzes the three categories around the suffixes -er and -ee especially. In the case of $\mathrm{N}_{1} \mathrm{~N}_{2}$ where $\mathrm{N}_{2}$ is an "eventive deverbal noun", she shows that $\mathrm{N}_{1}$ can be a subject or a complement and insists on the fact that "subject interpretations of compounds based on nominalizations in -ation or -ing" (p. 44) had long been believed to be impossible, notably by T. Roeper and D. Siegel [1978] or E. Selkirk [1982]. She then focuses on the "Event reading skeleton" vs the "result reading skeleton" (p.44) and on "Non-affixal (de)verbal compounds" in which "one element is always interpreted as an argument of the other" (p. 45-46). She thinks that she has greatly improved on the previous literature on the subject and says so explicitly: "the most thorough analysis, to my knowledge, is that given in Lieber [2010]" (p. 46). Yet in coordinate compounds, the notion of skeleton does not apply, which proves problematic, as written above. You might wonder why R. Lieber asserts that "The argument for exocentricity hinges on the hyponymy test: if we consider blue-green to be neither a sort of blue nor a sort of green, then the compound arguably might be considered exocentric" (p. 47, n5). Indeed, "blue-green" is supposed to be a certain kind of green, which is to say a green tinged with blue as opposed to "green-blue", which denotes a certain kind of blue tinged with green. It is clear that in such adjectival compounds one colour is deemed to be prevalent: the one denoted by $\mathrm{Adj}_{2} \mathrm{in}_{\mathrm{Adj}} \mathrm{Adj}_{2}$.

10 The concatenation of "lexical semantic representations" in the case of attributive compounds (p.49) is not really informative. This also goes towards proving that R. Lieber's approach is more descriptive than analytical, contrary to R. Jackendoff's where the clear-cut categories can be applied to a wealth of compounds. We might also ask ourselves whether the adjective "American" can be described as "- scalar" (p. 50 since the sentence "That's not a very American way to behave." could be acceptable. There is no thorough explanation of rock hard given that in the description "[+material ([i])] [-dynamic, +scalar ([j])]", which is not particularly legible, the reasons why *stone hard is ungrammatical are not stated. You may think it is a pity that none of the following adjectival compounds were provided as points of comparison: stone-blind, stone-cold, stone-deaf, stone-dead and * rock deaf, for instance. In the analysis of exocentricity, which is defined as being multi-faceted and draws on L. Bauer's theory [2010], the case of doctor-patient understood as "a single person who is both doctor and patient at once" (p. 52) might have been exemplified. It would have been interesting to check whether it features in any corpus or whether it is just a theoretical example.

11 Although the conclusion offers a recapitulation in the form of generalizations, the sentence "attributives are unrestricted in the relationships that can be expressed between compound members" [53] might have been expanded on. It could have been 
stimulating to know whether there is really not a single counterexample in any corpus or in the literature. R. Lieber deplores the fact that "frameworks like Distributed Morphology [Harley 2009]] or Borer's exocentric model [Borer 2013] still try to account for compounding within purely syntactic frameworks" (p. 53). Yet, readers may think that one theory can be enriched by another and that different frameworks might be complementary. The real challenge would be to offer simultaneously semantic and syntactical explanations so as to bring the two fields of research together instead of stressing that they are mutually exclusive.

\subsection{Chapter 4, "Compounding from an onomasiological perspective" by Pavol Štekauer}

P. Štekauer here completes two chapters he wrote in 1998 and 2005 to detail his theoretical framework, which differs from others including in terminology. According to him, the semasiological approach to word formation does not put enough emphasis on meaning, which explains why in the onomasiological framework, the word "compounding" is not used in the same way. Historically speaking, form and meaning were considered to be interrelated by F. de Saussure, the Prague School of Linguistics and then Cognitive Linguistics. The present article was written from the perspective provided by M. Dokulil [1962] and focuses on a "triad of relations" with a practical goal, a pragmatic one, in mind: "the extralinguistic reality", "the speech community" and "the word formation component (word formation rules)" (p. 55). The point of view is that of the language-user, which is very attractive because you can project yourself into the linguistic situations that are alluded to, the speech act being common to us all. While he does not use any abstractions or jargon the better to study productivity and language coiners' preferences, P. Štekauer does not forget to mention all the factors coming into play such as the socio- and psycholinguistic ones, which makes for a comprehensive theory. Clear definitions are provided whenever a term potentially unknown to readers is used, for example "onomasiological" and "onomatological".

In the second part, basic principles are proposed to illustrate the theory, which is founded on the speaker's cognition. Semantic categories "like Agent, Patient, Instrument, Location, Time, and Manner" are set in a system that centres on what the author calls:

the onomasiological mark (modifier in the mainstream approach), which specifies the base, consists of the determining constituent and the determined constituent, the onomasiological base standing for a class to which the object to be named belongs. (p. 56)

P. Štekauer clearly demonstrates how to apply "the Morpheme-to-Seme-Assignment Principle" (p. 57), which mobilizes both the paradigmatic and syntagmatic axes. He shows us how to represent "the onomasiological structure" (p.58) through simple examples like writer, novelist, guitar player and guitarist. He also reflects on the competition which takes place between two conflicting tendencies: one towards "semantic transparency", the other towards "economy of expression" (p. 58). It might have been of interest firstly to know how the choice between the suffixes -or, -er or -ist operates when it comes to determining the agent and secondly to carry out studies in compatibility. The mention of "different naming strategies" (p. 58) leads P. Štekauer to determine which complex words can be said to be either "listener/reader-friendly" or "speaker/writer-friendly" (p.58). It seems that the higher the degree of semantic 
transparency, the lower the degree of economy of expression, the more likely the word is to belong to the former category. For readers to know how to articulate word formation and word interpretation, interesting onomasiological "types" are then neatly developed, which enable the author to do away with terms like "prefixation, suffixation, back-formation, blending, conversion, reduplication". One example is the adjective "unhappy", which pertains to onomasiological type 7 (p. 61):

\begin{tabular}{|l|l|l|}
\hline OT 7 & Mark & Base \\
\hline & R & R \\
\hline & Negation & Quality \\
\hline & un & happy \\
\hline
\end{tabular}

The third part deals with the onomasiological analysis of compounds around four categories: SUBSTANCE, ACTION, QUALITY and CIRCUMSTANCE. The compound baby book is chosen as an instance of polysemy, which gives P. Štekauer the possibility to scrutinize meaning predictability. While opposing verbal compounds and primary compounds, he insists that exocentric compounds are not headless, contrary to what might have been written in the literature. According to him, "at the onomasiological level - the base is always present no matter whether or not it is represented at the onomatological level" (p. 63). To prove his point, he quotes the example of redskin, a compound which can denote a person, more precisely a Native American, or a potato. He makes it clear that "Not all exocentric compounds pertain to the same type" (p. 63). $\mathrm{He}$ also passes in review the other three categories - ACTION, QUALITY, CIRCUMSTANCE -, by illustrating them along the same lines, that is to say by choosing examples that are immediately understandable.

In the conclusion, a very clear visual representation of the "onomasiological model of complex words" (p. 67) helps you memorize the main points and compare this original approach to others: while reducing theoretical tools to a bare minimum without ever oversimplifying the discussion or jeopardizing the reasoning, it is easy to apply to all compounds.

\subsection{Chapter 5, "Categorizing the modification relations in French relational subordinative $[\mathrm{NN}]_{\mathrm{N}}$ compounds" by Pierre J. L. Arnaud}

In the introduction the author indicates that the framework he has chosen is that of Cognitive Linguistics and starts by summarizing its tenets. He thinks that it is necessary to expand on research carried out in the field:

we need descriptions and inventories of these relations in order to understand the processes and semantics of compounding. Such inventories are also necessary for comparative and computational linguistics. The aim of the research presented here is descriptive: to produce a taxonomy for French compounds and to compare French with English with respect to relations. (p. 72) subordinative $[\mathrm{NN}]_{\mathrm{N}}$ compounds" and the parallel between French and English 
coordinative and subordinative compounds, which are illustrated by a figure (p. 73). What proves useful here is the literal word-for-word paraphrase and the translation into English, which makes the specificity of French compounds stand out. It is manifest that there is a majority of "morphologically and syntactically left-headed" compounds in French (p. 73). A distinction is established between "semantically two-headed" coordinatives and "semantically single-headed" subordinatives in French (p. 72). The differences between the two languages are obvious when it comes to the pluralization of the non-head.

In the second part, P. Arnaud hints at research "on the semantics of English and French relational compounds" (p.74) to tell us more about the various theories that are organized around different categorizations of compounds. He goes back to A. Darmesteter's 1874 study, then to the late 1940s down to the present and tackles the problem of interpretation which precludes exhaustivity. Ambiguity is also at stake since some compounds suffer from the "vagueness of category descriptions" (p. 75). After analyzing the issues related to those taxonomies, he shows why the prepositional approach to French relational compounds was not reliable and why another classification was needed.

In the third part, he presents his initial research, which harks back to 2003, and gives explanations of the method he has chosen. He says it was necessary for him to use paraphrases which, for simplicity's sake, were kept as short as possible, and to keep in mind that there is "a continuum of abstraction in the categories" (p. 79). The numerous examples allow you to understand quickly the new taxonomy, which betrays the influence of A. Hatcher [1960] as well as of M. Noailly [1990]. They are followed by the presentation of four new categories: "ANALOG (denotes analogy in an aspect of the head), BE (denotes a state of the head), NON-HEAD SYMBOLIZES HEAD and NON-HEAD SYMBOLIZED BY HEAD" (p. 81). Then comes the "Application to an extended data set" (p. 81) with the aim of reaching "a more precise formulation of a relation to which these units clearly belong in the first place" (p. 82). This enables us to grasp why some new categories were added, which now brings the total to fifty-eight. The focus is then on the five most frequent relations which are illustrated in a table although one has to allow for some overlap between relations, a phenomenon that P. Arnaud links to what R. Jackendoff calls examples of "promiscuity". Compared to the latter's Conceptual Semantics model, P. Arnaud's is much less characterized by formalism. His comparison between French and English relational compounds is very stimulating as it enables us to get a better idea of the particularities of each language. He notices that the telic relation prevails in French relationals and underscores the complexity of compound semantics, "compounding consist[ing] basically in the pairing of concepts" (p. 89). Finally, the synthesis in the appendix, which does away with any complicated representation, is very clear and accessible even to students.

\subsection{Chapter 6, "The semantics of NN combinations in Greek" by Zoe Gavriilidou}

21 Zoe Gavriilidou first establishes a distinction between a sentence and a compound regarding the principle of compositionality understood from a semantic point of view. To highlight the specificity of compounds, she lists the research carried out by J. Levi, D. Cruse, P. Downing, B. Warren, V. Adams, N. Fabb, R. Dirven, M. Verspoor, R. Benczes, 
C.Gagné, T.Spalding, P. Štekauer and C.Charitonidis to infer that "major issues regarding especially the semantic interpretation of components remain open" (p. 96). Having chosen R. Lieber's framework, which, as she points out, is articulated around a semantic / grammatical skeleton and a semantic / pragmatic body, she nevertheless refers to S. Scalise and A. Bisetto's 2009 "tripartite classification of compounds" (p. 96). The focus is on NN combinations in Greek and the three subtypes applying to them, which differ in the relations between $\mathrm{N}_{1}$ and $\mathrm{N}_{2}$ as well as in the "degree of semantic transparency" (p.99). Several examples are given to illustrate the four semantic patterns at stake: coordinate NN combinations, attributive NN combinations, some of which have expressive non-heads, attributive NN combinations with denominational function and attributive $\mathrm{NN}$ combinations with expressive meaning.

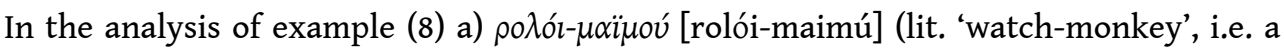
fake watch) (p. 103; 106), it might have been apt to quote the English verb to ape. In example (9), which is centred on the Greek compounds for "woman-psychologist" and "psychologist-woman", it might have been interesting to know in more detail why the nouns can be in the reverse order (p.103) and why there is no difference in connotation as the author says (p. 105). She later insists that "a coordinate interpretation is ruled out [in Greek] because the two elements are not given totally equal status", the Greek word for woman being used as a modifier (p. 108). She disagrees with S. Scalise and A. Bisetto on the question of the role of the skeleton: according to her, in Greek attributive NN combinations with expressive meaning as in French, Spanish or Italian, "the skeleton seems to play a role in making an evaluative or degree

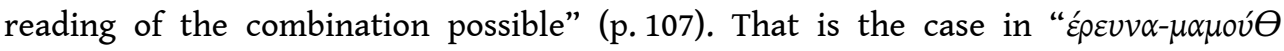
[erevna-mamou $\Theta$ ] (lit. 'research-mammoth')", which denotes "research that lasted for a long time and gathered lots of data" (p.106). In the concluding summary, she emphasizes the role of the skeleton in coordinate and attributive NN combinations with expressive meaning and the differences she has mentioned in Greek.

\subsection{Chapter 7, "The semantics of compounds in Swedish child language" by Ingmarie Mellenius and Maria Rosenberg}

This article, which gives us an overview of first language acquisition, is another crosslanguage study that widens the scope of the book. For the authors, creative coinages are the occasion to ask three questions related to the status of the morphological head in some children's compounds, the semantic relations within the NN compounds and their frequency. After first defining the characteristics of Swedish compounding, I. Mellenius and M. Rosenberg comment on the research in the domain, taking up H. Clark's five principles. They also refer to H. Clark and R. Berman [1987] as well as to J. Becker [1994] so that readers can set their own comparisons between Hebrew, English and Swedish regarding children's linguistic tendencies as they utter novel compounds or lexically innovate in any other way. I. Mellenius quotes her own $1997 \mathrm{PhD}$ thesis to show how children make progress when learning their mother tongue and how compounds as well as their constituents can be interpreted.

A presentation of both authors' corpus-based approach and of the semantic structure of NN compounds produced by Swedish children follows. We learn that the latter know where to place the head at a very early stage, i.e. when they are as young as three and a half, and that their interpretation is influenced by the context. The classification 
suggested by the authors, which is reminiscent of previous research, especially R. Jackendoff's 2009 and 2016 writings, is exemplified by five types of "Purpose relations". In the case of the "Part-whole relation", "a strict criterion" of use has been established, "which can be formulated as "one cannot take away the part without causing damage to the whole"' (p. 119). In example (11), motorbil 'motor-car', for 'car' (p.119), a parallel might have been drawn with English as people originally said "motor-car" and not just "car", that means of transport being a new invention at the time, as opposed to a horse-drawn vehicle, for instance. We can notice the same phenomenon in French, where "auto" is short for "automobile", i.e. "voiture à moteur". Regarding the "Whole-part relation", to which the authors decided to apply the same strict criterion of use, it might have been assumed in example (12) handfinger "handfinger', for 'finger' (p. 119), that the child included the noun "hand" maybe because he or she did not know the Swedish word used for toes. He or she might just have wanted to lay emphasis on the contrast with a view to making himself or herself understood. As far as the "Composition relation" is concerned, two different views are detailed, H. Clark's 1985 and J. Windsor's 1993, which were not shared by I. Mellenius as early as 1997. Indeed, she thought that "children's novel compounds most often manifest temporary relations" (p.120), thus setting well-established compounds apart from coinages. Two types of "Location relation" then come under scrutiny, but the explanation of example (20) kaffeglas 'coffee-glass' is debatable: the sentence "Our classification is based on a discourse situation where a coffee glass refers to a glass that happens to have coffee in it" (p.121) sounds odd given that in English we would then rather use the phrase "a glass of coffee". Indeed, "a coffee glass", which simply denotes a certain type of glass as opposed to "a wine glass" for instance, can be empty; the same distinction occurs between "a cup of coffee" and "a coffee cup" or "a cup of tea" and "a teacup".

The relations defined as Both: $N_{1}$ is $N_{2}$, Comparison: $N_{2}$ similar to $N_{1}$, Possession: $N_{2}$ belongs to $N_{1}$, Product: $N_{1}$ source for $N_{2}$, Source: $N_{2}$ source for $N_{1}$, Content: $N_{2}$ about $N_{1}$ and Protect: $N_{2}$ protects from $N_{1}$ make good reading before the study of argumental relations (p. 125). We might wonder about the inclusion of curling iron in the latter category: to what extent is it different from the purpose relation in that case? The authors have to complete the previous list with "Complex relations" that are "accidental" and due to "particular discourse situations" (p.125) before they can analyze the frequency of the semantic relations in a table. They can thus make clear what pertains to generalizations or to individual profiles (p.126). Their comment on the telic relation as being the most frequent (p.125) echoes P. Arnaud's remark about French relationals (p. 89). To conclude, I. Mellenius and M. Rosenberg stress the role of cognition in language acquisition and expand on the question of meaning by comparing children and adults: word creation cannot be studied without any insight into understanding, and although they are convinced that "we have no means of knowing" how established NN compounds are analyzed by the child, there is evidence of decomposition in the case of coinages. A lot remains to be discovered when it comes to NN compounds, especially novel ones, which is why both authors are glad to finally make interesting suggestions for further studies of context dependency and pragmatic explanations so as to explore in greater depth the adults' or children's linguistic usage. 


\subsection{Chapter 8 , "The semantics of primary NN compounds: from form to meaning, and from meaning to form" by Jesús Fernández- Domínguez}

This chapter starts with a comparison between P. Štekauer's and R. Jackendoff's theories to highlight their similarities and differences. After quoting previous semantic research on compounds by O. Jespersen, A. Hatcher, R. Lees, P. Downing and J. Levi, a definition of primary NN compounds is proposed while the problem of meaning predictability is tackled. The clear summary of the main characteristics of the onomasiological and of the semasiological approaches is articulated around the comparison between P. Štekauer's model and the traditional morphological approach. Then the focus shifts to the main features of Parallel Architecture as defined by R. Jackendoff, including function $F$ which links $N_{1}$ to $N_{2}$ and is preferred to R. Lees' paraphrasing (p.135). What is at stake in Conceptual Semantics is the number of meanings a compound may have and the potentiality of "promiscuity" in R. Jackendoff's phrasing. We are then faced with two options: either there is an actionargument relationship between the constituents of the compound or there is not, which is why there are two classes of compounds with different semantic relations.

The dissimilarities between the two theories regarding the labels used are summed up in two tables page 137. In P. Štekauer's model, "each of [his] labels is intended to be assigned to one compound constituent and the semantic link between them is left unexpressed" (p. 138) whereas in R. Jackendoff's it is specified and reversibility is studied. As far as COMP[osition] (X, Y) and MADE (X, FROM Y) are concerned, one might wonder whether there might be some overlap, a remark J. Fernández-Domínguez also makes in footnote 8 page 139. Several examples of the fundamental meanings within NN compounds are listed, among which no. (16), bird song $_{2}$, [SONG ${ }_{2}{ }^{\alpha}$; [MAKE (BIRD ${ }_{1}$, $\alpha$ )]], whose paraphrase "a bird that produces songs" sounds strange in lieu of "a song that is produced by birds". J. Fernández-Domínguez emphasizes two innovations introduced by R. Jackendoff: the "SIMILAR (X, Y)" and "PROTECT (X, Y, FROM Z)" relations. The differences between the two formalizations stand out all the more pages 139 to 142: P. Štekauer's is pared down to the minimum data while R. Jackendoff's does not forget any semantic detail.

The next subsection is devoted to what we learn about language as a whole when studying NN compounds: what roles are assigned to syntax, to the lexicon and to word formation? It is shown that syntax only intervenes in word formation through the lexicon: "the key is the different approaches adopted by PA and the onomasiological model towards the tasks of syntax in relation to word information" (p. 143). Although R. Jackendoff postulates the potential agent where necessary while P. Štekauer does not, although extralinguistic/pragmatic material features in PA but not in the onomasiological model, two figures illustrate three parallels between the two theories pages 144 and 145. Both linguists consider "word formation as a separate module" while they "strictly discriminate the roles of word formation and the lexicon, and forbid direct access between word formation and syntax". Their "interpretations of lexical entries" are "analogous in that in both cases the lexicon stores the syntactic, phonological and semantic information that cannot be recovered from word formation" (p. 145). To conclude, the author sums up this enlightening contrast as follows: "the onomasiological approach gives preference to the semantics derived 
directly from word formation, while PA is interested in the entirety of meaning" (p. 149).

\subsection{Chapter 9, "An analysis of phrasal compounds in the model of Parallel Architecture" by Carola Trips}

In this first article of the third part, which is "entitled "Other compound types", the emphasis is put on phrasal compounds, which, according to the author and contrary to what generative models might have led us to believe, combine morphology and syntax. To start with, it is useful to learn about the five properties she outlines so as to be able to tell phrasal compounds from non-phrasal compounds. The hyphen versus quotation marks ratios enable her to ponder the link to lexicalization and stress that regarding intonation new research is needed. She underlines the fact that phrasal compounds are a written phenomenon and that it is essential to set different categories for "pseudophrasal compounds" and "real phrasal compounds", in P. Hohenhaus' words (p. 158). The formal properties of the latter, which are determined by the presence or absence of a predicate, are all listed clearly pages $159-160$ before the links between heads and nonheads come under study pages 161-163. The recent research on phrasal compounds, especially A. Spencer's as well as R. Lieber and S. Scalise's, has stated the problem of "the lexical integrity hypothesis" that is not premised on any interaction between syntax and morphology.

Carola Trips then comments on recent German papers dealing with phrasal compounds to make her point through comparisons. She explains why she has chosen to apply R. Jackendoff's Parallel Architecture to English phrasal compounds and demonstrates why "For the interpretation of PCs containing a predicate, instances of metonymy are crucial" whenever "the semantic relation between the phrasal non-head and head is not direct" (p. 172). She then rightly schematizes her analyses before discussing R. Lieber's framework quickly and applying it to a couple of phrasal compounds so that readers get a clear idea of the contrast with R. Jackendoff's model.

\subsection{Chapter 10, "Adjective-noun compounding in Parallel Architecture" by Barbara Schlücker}

Among the differences between adjective-noun compounds and noun-noun compounds, the author throws into relief the fact that they do not have the same semantic relations although both categories are believed to share a "classifying meaning" (p. 178). While relying on R. Jackendoff's Parallel Architecture, she highlights the contrast between regularity and idiosyncrasy regarding noun-noun compounds "at least in Germanic languages such as English and German" (p. 179). She also outlines Construction Morphology as defined by G. Booij in 2010 to compare it with R. Jackendoff's framework and discuss schemas along with meaning relations. The distinction between classifying and non-classifying nominal compounds leads to the question of "the abstract semantic structure" (p. 181): where is the classifying meaning included? She also studies synthetic compounds and compounds with proper names, which are followed by a few of R. Jackendoff's similar examples page 182. As far as "beta cell" and "X-ray" are concerned, we might wonder whether they are real noun-noun compounds given that letters of the Greek and Latin alphabets are used instead of $\mathrm{N}_{1}$. 
32 In the case of adjective-noun compounds appearing in theories on concept categorization, examples might have come in handy to establish a distinction between "type concepts" and "token concepts" (p. 183) and thus render the paper less abstract. Barbara Schlücker, who draws on L. Ortner and E. Müller-Bollhagen's [1991], S. Simoska's [1999], W. Motsch's [2004] and her own 2014 pieces of research, points out that German adjective-noun compounds can be seen in Parallel Architecture as falling into "at least six semantic subclasses" (p. 185). This enables her to compare adjectivenoun compounds with "relational adjectives of the non-native type and their relation to corresponding noun-noun compounds" (p. 185) with the aim of broaching the topic of semantic specialization. After quoting a few instances of German adjective-noun compounds in which the adjective directly modifies the head noun, she focuses on possessive compounds whose interpretation is this time metonymic. She is also interested in adjectives with an adverbial function or which are used not as modifiers but as implicit nominal arguments, as well as in compounds that have a causal meaning component. She stresses that "noun-noun compounds can be classified according to the particular semantic modification relation involved" (p. 189), which is not the case of adjective-noun compounds although both are classificatory in meaning. The last subclass she discusses is that of adjective-noun compounds with relational adjectives before she concludes on the new function she proposes: IS A SUBTYPE OF "which takes the subconcept and the superconcept as its arguments" (p. 191).

\subsection{Chapter 11, "Neoclassical compounds in the onomasiological approach" by Renáta Panocová}

33 The author of this paper, who has chosen the onomasiological perspective, ponders the neoclassical compounds that mostly feature in technical and scientific papers, which implies examining their degree of transparency and their productivity. While contrasting the combinations of two bound stems and of one bound stem plus a word, she wonders whether neoclassical compounds constitute a distinct class within the category of compounds and where to place the boundary between word formation and borrowing. The problems with terminology stem from the absence of consensus on bound stems and the confusing definition of neoclassical elements in the literature as either affixes, prefixes or suffixes, or as "combining form[s]" by the Oxford English Dictionary (p. 194). L. Bauer used the phrases "Initial combining form" and "final combining form" in 1983 and 1998, when S. Scalise and A. Bisetto talked about "semiwords" in 2009 and P. ten Hacken about "neoclassical formatives". M. Aronoff did not see them as "entities of their own" in 1976 just like A. Lüdeling et al. in 2002, who did not determine any precise status for them. To make things clearer though, P.ten Hacken proposed a test as early as 1994 "to determine whether an element is a stem or an affix" (p. 194).

34 Contrary to M. Aronoff and A. Lüdeling, R. Panocová herself is of the opinion that " $[t]$ he delimitation of the morphological status of neoclassical elements has a direct impact on the definition of the morphological process which combines them" (p. 195). She is keen on showing the differences between the onomasiological and semasiological approaches to specify "neoclassical formatives" or "neoclassical combining forms" within P. Štekauer's framework. According to her, these phrases, which seem more appropriate because P. Štekauer does not refer to "affixation, compounding, blending 
and conversion", correspond to the status of "linguistic signs": compounds have a meaning and a form although they differ from affixes in the sense that "the direction of attachment" is not given (p. 197). Before quoting several examples from the OED, she comes back to P. Štekauer's onomasiological type, OT, and to his onomasiological structure, which consists of "the onomasiological base (OB) and the onomasiological mark (OM) divided into the determined and determining constituents" (p. 198). After this didactic parenthesis, she analyzes a few complex neoclassical compounds and notices that the principle of linguistic economy prevails, which is why P. Štekauer refers to types 3 and 4 as "speaker/writer-friendly, but less listener/reader-friendly" (p. 202). She also alludes to her own 2014 research, which enabled her to assert that "the number of neoclassical words resulting from back-formation is relatively high" (p. 203). The comparison between English and Russian corpora is a revealing sign of the importance of "[w]ord formation and borrowing in the onomasiological theory" (p. 203) as summarized in the conclusion: "Systematic and rule-governed neoclassical word formation as found in English is covered in the word formation component whereas neoclassical formations in the form of borrowings, as found in Russian, belong to the domain of the Lexicon" (p. 207).

\subsection{Chapter 12, "Three analyses of compounding: a comparison" by Pius ten Hacken}

This chapter, which serves as an effective conclusion, starts with the dichotomy between "classification and interpretation" (p. 211). P. ten Hacken draws up a list of the problems inherent in previous theories the better to compare the three frameworks presented in the volume. He specifies where the focus is in each of them and sums up the main points before illustrating the three approaches by applying their principles to the same compounds, mainly from Dutch. Examples of primary nominal compounds are followed by those of verbal compounds, to which they are opposed in the generative tradition, and by those with verbal non-heads. The final synopsis of the "similarities and differences" is a very useful reminder to readers who might not have read all the chapters.

\section{Remarks}

Although the layout is very neat, a larger and darker font as well as a wider spacing would have been gentler on the eyes, and all the more so as the analyses are often quite abstract.

\section{Strong points}

The great asset of the book is the detailed contributions by specialists in the field and, among them, the three theoreticians whose frameworks are highlighted. The rational plan that has been chosen allows a gradual progression from theory to practice and from generalities to particularities. Such didactic props as summaries, numbered sections and subsections as well as figures and tables enable any reader to understand quickly what compounding is all about. The scope of the book is greater thanks to the different types mentioned: the authors do not just deal with Noun + Noun, but also with 
Adjective + Noun and neoclassical compounds. The cross-language studies that have been carried out give you the opportunity to learn more about foreign languages such as French, German, Swedish or Greek and as a result, about the specificities of English. The issues of meaning and interpretation come across as being central and show why semantics can no longer be bypassed in theories that aim to be as comprehensive as possible. Because of those qualities, The Semantics of Compounding is indeed a must-read!

\section{BIBLIOGRAPHY}

ADAMS Valérie, 1973, An Introduction to Modern English Word Formation, London: Longman.

ALLEN Margaret Reece, 1978, Morphological Investigations, PhD thesis, University of Connecticut.

ARONOFF Mark, 1976, Word Formation in Generative Grammar, Cambridge University Press.

BECKER Judith A., 1994, “'Sneak-shoes', 'sworders', and 'nose-beards': A case study of lexical innovation', First Language, Volume 14, 195-211.

BENCZES Réka, 2006, Creative Compounding in English, Amsterdam/Philadelphia: John Benjamins. BAUER Laurie, 2010, “The typology of exocentric compounding”, in SCALISE \& VOGEL (Eds.), CrossDisciplinary Issues in Compounding, 167-176.

B0oIJ Geert, 2010, Construction Morphology, Oxford University Press.

BORER Hagit, 2013, Taking Form, Oxford University Press.

CHARITONIDIS Chariton, 2014, "The linking of denotational and socio-expressive heads in Modern Greek and English compounding”, Italian Journal of Linguistics, Volume 26, no. 2, 9-50.

CLARK Eve V. \& BERMAN Ruth A., 1984, "Structure and use in acquisition of word-formation", Language, Volume 60, 542-590.

CLARK Herbert H., 1996, Using Language, Cambridge University Press.

CRUSE D. Alan, 1991, Lexical Semantics, Cambridge University Press.

DARMESTETER Arsène, 1874, Traité de la formation des mots composés dans la langue française comparée aux autres langues romanes et au latin, Paris: Franck.

DIRVEN René \& VERSPOOR Marjolein, 1998, Cognitive Exploration of Language and Linguistics, Cognitive Linguistics in Practice 1, Amsterdam: John Benjamins.

DOKUKIL Miloš, 1962, Tvoření slov v češtině I. Teorie odvozování slov, Prague: Nakladatelství Československé akademie věd.

DOWNING Pamela, 1977, "On the creation and use of English compound words", Language 53, 810-842.

FABB Nigel, 1998, “Compounding”, in SPENCER Andrew \& ZWICKY Arnold M. (Eds.), The Handbook of Morphology, Wiley-Blackwell, 66-83. 
FILLMORE Charles \& ATKINS Sue, 1992, “Toward a frame-based lexicon: The semantics of RISK and its neighbors", in LEHRER Adrienne \& FEDDER Kittay Eva (Eds.), Frames, Fields, and Contrasts, Hillsdale, NJ: Erlbaum, 75-102.

GAGNÉ Christina L., 2001, "Relation and lexical priming during the interpretation of noun-noun combinations", Journal of Experimental Psychology: Learning, Memory \& Cognition 1, 236-254.

HARLEY Heidi, 2009, “Compounding in distributed morphology”, in LIEBER Rochelle \& ŠTEKAUER Pavol (Eds.), The Oxford Companion of Compounding, Oxford University Press, 129-144.

HATCHER Anna Granville, 1960, “An introduction to the analysis of English noun compounds", Word, Volume 16, 356-373.

HOHENHAUS Peter, 1998, "Non-lexicalizability as a characteristic feature of nonce word formation in English and German", Lexicology, Volume 4, no. 2, 237-280.

JACKENDOFF Ray, 2002, Foundations of Language: Brain, Meaning, Grammar, Evolution, Oxford University Press.

JACKENDOFF Ray, 2009, “Compounding in the Parallel Architecture and Conceptual Semantics", in LIEBER Rochelle \& ŠTEKAUER Pavol (Eds.), The Oxford Companion of Compounding, Oxford University Press, 105-129.

JESPERSEN Otto, 1942, A Modern English Grammar on Historical Perspectives. Part VI: Morphology, Copenhagen: Munksgaard.

KATZ JERROLD J. \& POSTAL Paul M., 1964, An Integrated Theory of Linguistic Descriptions, Cambridge, MA: MIT Press.

LANGACKER Ronald W., 1987, Foundations of Cognitive Grammar, Volume I, Theoretical Prerequisites, Stanford University Press.

LEES Robert B., 1960, The Grammar of English Nominalizations, Bloomington: Indiana University Press and The Hague: Mouton (reissued 1963. $5^{\text {th }}$ printing 1968).

LEVI Judith N., 1975, The Syntax and semantics of non-predicating adjectives in English, PhD thesis, University of Chicago.

LIEBER Rochelle, 2004, Morphology and Lexical Semantics, Cambridge University Press.

LIEBER Rochelle, 2006, "The category of roots and the roots of categories. What we learn from selection in derivation", Morphology, Volume 16, 247-272.

LIEBER Rochelle, 2009, “A lexical semantic approach to compounding”, in LIEBER Rochelle \& ŠTEKAUER Pavol (Eds.), The Oxford Companion of Compounding, Oxford University Press, 79-104.

LIEBER Rochelle, 2010, “On the lexical semantics of compounds: Non-affixal (de-)verbal compounds", in SCALISE Sergio \& VOGEL Irene (Eds.), Cross-Disciplinary Issues in Compounding, 127-144.

LIEBER Rochelle, forthcoming, "On the interplay of facts and theory", in SIDDIQI Daniel \& HARLEY Heidi (Eds.), Morphological Metatheory, Amsterdam/Philadelphia: John Benjamins.

LÜDELING Anke, SCHMID Tanja, and KIOKPASOGLOU Sawwas, 2002, “On neoclassical word formation in German", in BOOIJ Geert \& VAN MARLE Jaap (Eds.), Yearbook of Morphology 2001, Dordrecht: Kluwer, 253-283.

MELLENIUS Ingmarie, 1997, The acquisition of nominal compounding in Swedish, PhD thesis, Lund University Press. 
мотSCH Wolfgang, 2004, Deutsche Wortbildung in Grundzügen.2., überarbeitete Aufl., Berlin, New York: de Gruyter.

NOAILLY Michèle, 1990, Le Substantif épithète, Paris: Presses Universitaires de France.

ORTNER Lorelies and MÜLLER-BOLLHAGEN Elgin, 1991, Deutsche Wortbildung: Typen und Tendenzen in der Gegenwartssprache, Vierter Hauptteil: Substantivkomposita, Berlin, New York: de Gruyter.

ROEPER Thomas, and Siegel Muffy, 1978, "A lexical transformation for verbal compounds",

Linguistic Inquiry, Volume 9, 199-260.

SCALISE Sergio \& BISETTO Antonietta, 2009, “The classification of compounds", in LIEBER Rochelle \& ŠTEKAUER Pavol (Eds.), The Oxford Companion of Compounding, Oxford University Press, 34-53.

SCHLÜCKER Barbara, 2014, Grammatik im Lexikon. Adjektiv+Nomen-Verbindungen im Deutschen und Niederländischen, Linguistiche Arbeiten 553, Berlin, Boston: de Gruyter.

SELKIRIK Elizabeth O., 1982, The Syntax of Words, Cambridge, MA: MIT Press.

SIMOSKA Silvana, 1999, "Die morphologische und semantische Vielfalt des Adjektiv+NomenKompositums", Deutsche Sprache, Volume 27, 156-187.

SPALDING Thomas L., GAGNÉ Christina L., MULLALY Allison C. \&HONGBo Ji, 2010, "Relation-based interpretations of noun-noun phrases: A new theoretical approach", in OLSEN Susan (ed.), New Impulses in Word-Formation, Hamburg: Buske, 283-315.

SPENCER Andrew, 2005, “Word-formation and syntax", in LIEBER Rochelle \& ŠTEKAUER Pavol (Eds.), The Oxford Companion of Compounding, Oxford University Press, 73-97.

ŠTEKAUER Pavol, 1998, An Onomasiological Theory of English Word-Formation, Amsterdam: John Benjamins.

ŠTEKAUER Pavol, 2005, Meaning Predictability in Word-Formation, Amsterdam, Philadelphia: John Benjamins.

WARREN Beatrice, 1978, Semantic Patterns of Noun-Noun compounds, Göteborg: Acta Universitatis Gothoburgensis.

WINDSOR Jennifer, 1993, "The function of novel word compounds", Journal of Child Language, Volume 20, 119-138.

\section{AUTHOR}

\section{CATHY PARC}

Cathy Parc, ICP, France

Cathy Parc is Senior Lecturer in English at ICP, coordinator of English teaching at the Pôle Langues. She holds a Ph.D. in English Studies from the Sorbonne Université-Paris IV, and has passed the "agrégation" in English with a major in Linguistics. She is the author of Calvin et Hobbes de Bill Watterson. La philosophie du quotidien (Paris: L'Harmattan, 2013. ISBN 978-2-343-00054-1. 132 p.), a French translation of Elizabeth Jennings' s Collected Poems 1953-1985 (Paris: L'Harmattan, 2014. ISBN 978-2-343-04434-7, EAN 9782343044347.640 p.), L'anglais du monde politique (Paris: Technip et Ophrys Éditions, Collection anglais de spécialité, 2014. ISBN 978-2-7080-1401-5. ISBN 978-2-7080-1402-2. Vol. 1: 280 p. Vol. 2: 224 p.), and English Words for Economics. Vocabulaire anglais contemporain de l'économie (Paris: Éditions Ellipses, 2015. 
ISBN 9782340-008373. 384 p.). She has published articles on linguistics and literature, especially poetry, as well as several book reviews in Lexis. 